\title{
A POESIA NO PENSAMENTO DE MARTIN HEIDEGGER E PAUL ZUMTHOR
}

\section{POETRY IN MARTIN HEIDEGGER AND PAUL ZUMTHOR}

Mariana Lage Miranda*

Yasmin Pires**

RESUMO: Sob a regência dos valores modernos de racionalidade e fico parecem embotar nosso racioćnio tom signi em significados prontos e discursos pretensamente verdadeiros. Por outro lado, em uma dimensão artística que foge às sistematizações imanentes a esse contexto, podemos nos ver diante de uma experiência diferenciada - a da plurivocidos nos ver dañe de un cichtido que não se pretendem unívocas. Nesta persectiva, este atigo sentido que nă se pretendíl univocas. Nesta perspectiva, este artigo Pauj Zum hor no que concerno à investigacão de Martin Heidegger PaulZum campo privil no que concented àve

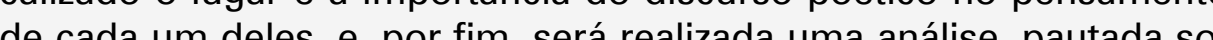
bru Zumther a noça heideggerian de velamento/desvelamento do Ser.

PALAVRAS-CHAVE: Poesia; Linguagem; Martin Heidegger; Paul Zumthor; Movência

* marianalagem@gmail.com

Pós-doutoranda, com bolsa Capes/PNPD, na Universidade Federal de Juiz de Fora (UFJF). Doutora em Estética e Filosofia da Arte pela UFMG.

* yasminpiresf@gmail.com

Mestre pelo Progra de Pós-Graduação em Filosofia da

Universidade Federal do Pará (UFPA), bolsista CAPES.

ABSTRACT: Under the modern values of rationality and objectivity, daily life and culture around scientific knowledge seem to dull our reasoning into ready-made meanings and allegedly true discourses. the other hand, in an arisic dimension, itesc that are immant in this context, we can find ourselves faced with a differe in anteren significations, in the transit between layers of meaning that are at in to the pork of Martin Heide aims at esZumthor in what conerns the investigation of poetry as a pril Pau field of in what concerns the investigation of poetry as a privileged Zield of in what concen of each on of them. Finolly, the ore will be an analysis based though of each one of them. Finally, there will be an analysis based mainly on and the Heideggerian notion of veiling/unveiling of Being.

KEYWORDS: Poetry; Language; Martin Heidegger; Paul Zumthor; Mouvance 


\section{A POESIA EM UM VIÉS PRIVILEGIADO}

$\mathrm{Na}$ fase inicial da obra de Martin Heidegger (1889 - 1976), o Ser é o elemento central de sua investigação filosófica. Em sua busca pela efetivação de uma proposta que confronta toda a tradição de estudos, Heidegger acaba por ocupar lugar de destaque no cenário da produção intelectual contemporânea. Na sua concepção, seria imprescindível o reconhecimento de um fim da filosofia pautada na metafísica clássica para que fosse possível alcançar um recomeço. Com isso, sob a alegação de que a história da filosofia é marcada pelo esquecimento do Ser - enquanto problema em desvelar uma unidade capaz de lidar com a multiplicidade de significações das coisas -, Heidegger lança mão de um conjunto de estruturas ontológicas fundamentais que possa alcançar a maneira com que produzimos significações. O caminho teórico de desenvolvimento e de compreensão dessas estruturas levará o filósofo, posteriormente, a explorar o domínio da linguagem como âmbito em que o Ser pode se manifestar, na medida em que ela é uma das formas por meio das qua is conhecemos e criamos o mundo que nos circunda. Inserida no curso dessa perspectiva, a poesia emerge como um modo diferenciado de abertura para o desvelamento do Ser, posto que, nela, a linguagem foge da representação comum das coisas e se reaviva em uma miríade de possibilidades. A linguagem seria, portanto, um componente essencial no seio da filosofia heideggeriana.
Por outro lado, em um percurso diverso, mas influenciado pela fenomenologia hermenêutica, Paul Zumthor (1915-1995) pesquisa os processos de percepção que permeiam nossa relação com as significações poética, por meio da literatura e da oralidade. Performance e movência são noções comuns à sua obra, que tendem a promover uma revalorização dos modos de comunicação oral e poética. Nesse sentido, o a utor sugere que nossa percepção do sentido de um texto se transformou a partir da invenção da imprensa de Gutenberg, de forma que a materialização da palavra no livro, aliada à ascensão e à consolidação do pensamento moderno, insuflariam a busca por significados unívocos e estáveis. Seu trabalho evidencia, assim, uma oposição entre a leitura pautada pela fixidez da palavra literária/escrita e a percepção performativa suscitada pela palavra poética/oral, isto é, pelo nomadismo da voz - sendo que esta última, a voz, em sua forma característica, daria ensejo a uma multiplicidade de percepções, vindo daí a noção de movência, sobre a qual nos voltaremos mais adiante.

Nos contextos que lhes são próprios, é perceptível que tanto na abordagem de Heidegger como na de Zumthor, a poesia assume um lugar privilegiado. Em vista desse paralelo, este artigo visa apresentar o local da poesia no pensamento de cada autor, e ainda, uma análise de como as propostas de cada um confluem na direção de um elogio 
à poesia, sobretudo, no que diz respeito à pluralidade de significações oferecidas por ela como um espaço distinto da linguagem.

Conceitualmente, este entrelaçamento proposto se dá, em síntese, entre a noção heideggeriana de velamento/desvelamento do Ser e a concepção de movência encontrada na obra de Zumthor. Assim, para que se possa efetuar a presente análise será realizado um breve levanta mento dos esteios do pensamento de cada um dos autores, para, em seguida, situar de que forma a poesia adentra suas respectivas abordagens, com o objetivo de mostrar, ao final, como a mbos - Heidegger e Zumthor - podem cruzar ca minhos em seus estudos acerca da linguagem poética.

\section{MARTIN HEIDEGGER}

O trabalho de Martin Heidegger pode ser considerado como fruto de um tempo no qual a filosofia encontrava-se sob forte crise: no final do século XIX e início do século $\mathrm{XX}$, frente ao crescente prestígio adquirido pelas ciências empíricas, havia demanda patente por um tratamento referencial dos objetos. A metafísica clássica não respondia a essas expectativas, e, consequentemente, os sistemas filosóficos tradicionais da Alemanha, tal qual o idealismo, entravam em declínio. Nesse momento histórico, surge a fenomenologia de Edmund Husserl, professor que influencia grandemente o começo do pensamento heideggeriano, e sob cuja tutela Heidegger inicia sua carreira acadêmica e filosófica. É com vistas a um novo tratamento referencial aos objetos que Husserl propõe a epoché transcendental, ou redução fenomenológica, como possibilidade de retorno não às coisas mesmas, mas ao modo como elas aparecem à consciência. Nesse cenário, Heidegger apa rece como um pensador marcado pelas cisões que propôs para a tradição filosófica. O cenário estabelecido e suas influências intelectuais levaram-no a repensar as questões que norteavam a filosofia e suas investigações, em um tipo de enfoque histórico em torno da natureza dos objetos que vinham ocupando o cerne dos estudos filosóficos. Seguindo este ca minho teórico, o que Heidegger veio a sugerir de fato foi que a metafísica deveria chegar a um fim para que a filosofia pudesse ter seu recomeço.

No intuito de alcançar esta proposta, Heidegger cunhou um novo vocabulário e novas estruturas, as quais podem ser entendidas como um conjunto de estruturas ontológicas funda mentais. Antes de tratar delas, no entanto, é necessário explicitar os principais elementos que compõem sua análise Em uma divisão acadêmica amplamente aceita, existe uma distinção entre "o primeiro" e "o segundo" Heidegger que, no decorrer desta pequena apresentação, será escla recida.

No primeiro Heidegger, reside a preocupação de dar uma definição precisa das estruturas anteriormente mencionadas 
1. CF. HEIDEGGER. Ser e tempo, p. 27-41.

2. Cf. DANTAS. O papel da linguagem no pensamento de Heidegger, $\mathrm{p}$ 18.
- o que se estabelece em sua obra Ser e Tempo como o tratamento de uma "diferença ontológica". ${ }^{1}$ Desta forma, seus esforços se baseiam no escla recimento da distinção entre Ser e ente. Sumariamente, o ente diz respeito a tudo o que $e ́$, a tudo o que existe na efetividade, a dizer, no tempo e no espaço. Ao mesmo tempo, é o que se encontra já estabelecido como coisa dada e definida. A mesa é um ente, a cadeira é um ente e nós mesmos o somos. Por sua vez, o Ser é o que determina os entes tal como entes, ou seja, o Ser é o que dá a existência deles em si mesmos, ${ }^{2}$ mas, mais do que isso, o Ser é o dinâmico e a abertura. Logo, o Ser ta mbém pode ser compreendido como o indefinido - o nada em seu sentido de plenitude, de algo que não se encontra circunscrito ou apreensível de modo totalizante. Esse enigma, que habita a ausência de possibilidade de conceituação do Ser, é o que motiva a obra heideggeriana.

Afora estes elementos, existe outra estrutura que faz parte da construção da ontologia fundamental de Heidegger e que se apresenta como meio de acesso ao Ser: o Dasein, ou ser-aí. Ele está contido em nós, seres humanos, mas - é importante frisar - não corresponde ao ser humano em si. É um ente que porta uma condição diferenciada, uma vez que carrega consigo a capacidade de compreensão do Ser, ou seja, ele permite um despertar genuíno para questões existenciais que só podem ser leva ntadas pelo ser humano.
Além desse aspecto, a característica elementar do Dasein é que ele habita em nós como uma condição de abertura que nos fornece os meios necessários para alcançarmos a efetividade. É por meio dele, então, que nós entramos em conta to com tudo o que nos circunda, pois tem uma condição preliminar de abertura que nos permite agir, pensar e conhecer as condições de mundo. ${ }^{3} \mathrm{O}$ Dasein se dá, portanto, enquanto um movimento de acesso aos demais entes manifestos, ao mesmo tempo em que mantém uma ligação com a compreensão do Ser em sua essência. Por isso, rigorosamente falando, reconhecer esta capacidade da qual o Dasein nos mune implica dizer que somente o ser humano existe. A árvore é, a pedra é, mas nós existimos, porque a existência (ek-sistência) trata exatamente de uma condição de abertura alusiva ao homem, de ser-no-mundo, na qualidade de detentor do Dasein. ${ }^{4}$

Após essa rápida explanação das estruturas ontológicas, é possível explicarmos, naquele contexto caracterizado por uma crise dos saberes, do que se trata o começo do ca minho filosófico empreendido por Heidegger. Ao inserir-se em uma reflexão acerca do conhecimento produzido pela filosofia até aquele momento, o filósofo verifica que, desde Aristóteles e Platão, houve uma sistemática (re) instauração de um pensamento que favorece os entes em suas efetividades históricas em detrimento do Ser em sua
3. NUNES. Heidegger e a poesia, $\mathrm{p}$ 106.

4. HEIDEGGER. Conferências e escritos filosóficos, p. 257.
EM TESE

BELO HORIZONTE

v. 23

N. 3

SET.-DEZ. 2017

MIRANDA; PIRES. A poesia no pensamento de Heidegger e Zumthor

P. $190-208$ 
5. GIACÓIA. Heidegger urgente, p. 44.

6. Cf. DANTAS. O papel da linguagem no pensamento de Heidegger, $\mathrm{p}$

20

7. CASANOVA. Compreender Heidegger, p. 98. condição de abertura. Ante esse fato, Heidegger identifica a necessidade de uma destruição dessa tradição filosófica Nessa perspectiva, a mobilização heideggeriana de uma diferença ontológica a partir de noções como "Ser" e "ente cumpre a função de resgatar o Ser do esquecimento histórico ao qual fora relegado. ${ }^{5}$

A fim de promover uma reversão do panorama que identificara, Heidegger propôs a destruição da metafísica principal responsável por ter relegado o Ser à obscuridade. Porém, quando Heidegger se referia à “destruição", ele não visava uma aniquilação ou desprezo, mas uma apropriação consciente, seguida de uma superação de seus preceitos, fundamentalmente no que diz respeito à definição do homem enqua nto a nimal racional. Isto significa que, na medida em que o homem se torna um sujeito do conhecimento ele é a fastado de sua essência original, pois o racionalismo vigente é herdeiro de uma tradição filosófica que nos condiciona a modelos de interpretação que se direcionam exclusivamente a entes específicos como horizonte investigativo. ${ }^{6}$ Assim, estudando o que tomamos restritamente como o dado na efetividade (ente), a fastamo-nos da investigação fundamental da essência das coisas, do que lhes dá unidade o Ser, independente de suas múltiplas significações.?

Frente a esta problematização, o trabalho de Heidegger volta-se para o estabelecimento de uma ontologia funda mental, baseada na desconstrução da metafísica e no estudo das estruturas e especificidades do Dasein (como, por exemplo, suas qualidades de ser-no-mundo e ser-para-a-morte). Enfim, cunhando uma concepção de fenomenologia própria, o filósofo tem como objetivo último elucidar o que determina o Ser, em geral.

\subsection{LIDA COTIDIANA}

Conforme dito, a supremacia de uma tradição metafísica que prioriza um olhar sobre os entes é algo sintomático para Heidegger. Para ele, ao nos dirigirmos aos entes, submergimos em uma esfera cotidiana que tende a lidar de forma rasa com o que nos circunda, pois elimina reflexões que sejam pertinentes à questão do Ser. Esse ponto referente à lida cotidiana, que se restringe aos entes, está direta e, ao mesmo tempo, inversamente relacionado ao movimento de abertura do Dasein. Em sua dinâmica de ultrapassagem do indivíduo em direção ao mundo, o Dasein pode ser marcado por dois momentos. Primeiramente, em um estado de contingência, ele é um projeto pronto para lançar-se, aberto às potencialidades de compreensão do Ser, em sua mais rica multiplicidade. Em segundo momento, lançado no cotidiano e dominado pelos entes, ele se limita. Quando nos dirigimos aos entes, como na ciência, na técnica, na lógica ou na metafísica, visamos objetos cujo sentido ou significação está cerrado em uma compreensão 
8. NUNES. Heidegger e a poesia, p.

9. NUNES. Heidegger e a poesia, $\mathrm{p}$ 107. previa mente instituída. Por conseguinte, no cotidia no lidamos com conhecimentos pré-estabelecidos e pensamentos prontos.

Aprisionados nesta visão, tudo o que está ao nosso redor é visto sob uma funcionalidade específica, como um utensílio a ser manuseado - e isto finda por relegar o Ser das coisas ao esquecimento. Se os objetos ao meu redor são vistos como meros instrumentos, estou lidando com ele de forma vaga, pois a faceta de instrumento é só uma das inúmeras possibilidades de mostração desse objeto. ${ }^{8}$ Posto isto, verifica-se que é desse modo que o Dasein, enquanto um projeto de possibilitação de inúmeras possibilidades, se delimita. No entanto, à despeito dessa situação pertinente à lida cotidiana, ressalta-se que o Dasein é passíve de processos de singula rização, que permitem que o Ser apesar de historicamente negligenciado, seja vislumbrado No processo de singularização, o Dasein tem a oportunidade de sair da latência da vida cotidiana para atender à sua essência, buscar a si mesmo, que nada mais é do que voltar-se para a questão do Ser. Consequentemente, ele passa a visar o que pode ser, e não somente o que $e^{9}$. Dessa forma, segundo Oswaldo Giacóia, em sua estrutura ontológica o Dasein pode se abrir para o Ser por meio de três formas: primeiro, a afinação ou tônus afetivo (Stimmung) segundo, a compreensão; e, por fim, a fala, no sentido do discurso, da linguagem. ${ }^{10}$ A este artigo interessa o último tema, no qual se situa a poesia como lugar privilegiado de manifestação do Ser.

2.2 POESIA COMO MODO PRIVILEGIADO DE ABERTURA Para Heidegger, a retomada da pergunta pelo Ser exige uma apreensão fenomenológica do ser humano, do mundo e da linguagem..$^{11}$ Isto porque, nos termos de sua fenomenologia, a qual investiga o Dasein, a linguagem é uma importante ferramenta para se lançar no mundo. Ademais, ela é relevante para Heidegger por revelar-se em um tipo de ato de comunicação que nos diferencia dos animais, designando-nos como "criaturas da linguagem". Enqua nto elemento central do Dasein, ela nos dá a capacidade de conhecer. ${ }^{12}$

Concomitantemente, por concernir ao Dasein, a linguagem está sujeita aos processos afeitos à mundanidade da lida cotidiana anteriormente citados: no dia a dia, ela comumente se aliena do pensamento e se aparta da experiência originária do logos, ao ser tomada como mera correspondência entre palavra e coisa. Isto quer dizer que, se a linguagem for, dentro dessa visão técnica, entendida como simples signo, ela será operada em um sistema de referencialidade que afasta potenciais possibilidades de significação, trabalha ndo em cima do que se é, puramente, e reduzindo assim o espectro de significação potencial da
10. GIACOIA. Heidegger urgente, p. 76.

11. DANTAS. O papel da linguagem 18

2. HEIDEGGER. Sobre a essência da linguagem, p. 8 
13. GIACOIA. Heidegger urgente, p. 78.

14. GIACÓIA. Heidegger urgente, $\mathrm{p}$. 96. linguagem. Em direção inversa, contudo, isto é, não meramente técnica, a linguagem tem a capacidade de mostrar, no sentido de fazer ver, aquilo de que fala o discurso. Efetivamente, é ela quem torna os entes manifestos, mas, ainda em sua propriedade de instrumento do Dasein, ela pode singularizar-se e abrir-se para o vislumbre do Ser. ${ }^{13}$

Quando estamos fora da esfera cotidiana, tornamo-nos passíveis a receber o chamamento do Ser. Nesta condição, podemos vivenciar a verdade, a qual pode manifestar-se por meio da linguagem. Todavia, para Heidegger, a verdade implica necessariamente uma dinâmica de velamento e consequente desvelamento do Ser, porque este nunca se revela por completo. Antes, ele se define por este limiar, por um movimento contínuo em que é descoberto ao mesmo tempo que é encoberto, já que o Ser é indefinível, inconceituável, a mplo de possibilidades. Este encobrimento (ou mesmo esquecimento) é, portanto, constitutivo do Ser, o que Heidegger designa como uma condição de errância "Ex-istir, no sentido de abertura, é corresponder linguageiramente ao chamamento do Ser, ao descerrar-se do Ser aos entes em seu desocultar. Temos que pensar em Ser e nada, pois Ser é nada de ente [...]. É um vazio, o imponderável a partir do qual se dá o mesmo gesto mais fugaz." 14

Uma vez que a linguagem é esse espaço de abertura em que o velamento e desvela mento pode se concretizar, a poesia assume um lugar diferenciado, pois preserva exatamente a abertura da palavra, descartando o pensamento técnico, representacional. Assim, a poesia fala em detrimento de toda metafísica e ciência direcionadas aos entes, não mais transmitindo uma interpretação comum das coisas, antes, verdadeiramente reavivada pelo poético, ela aponta para a ampla possibilidade do Ser. ${ }^{15}$

$\mathrm{Na}$ poesia, somos então convidados a perceber a manifestação de abertura da linguagem de modo que podemos acessar a verdade de algo que faz parte de nós - o Ser. Ela dirige-se ao nosso próprio Ser, e não ao Dasein. ${ }^{16}$ Com isso, pode-se considerar que, nela, o sentido se oculta ao mesmo tempo em que se revela, porque, neste contexto, ela não carrega a meta de sentido da lida cotidiana. Se a filosofia para Heidegger é a busca pelo Ser que outrora fora relegado ao esquecimento, e se a poesia é um modo diferenciado de abertura para a manifestação da verdade, o pensador e o poeta são agentes privilegiados que revela m a linguagem enquanto clareira do Ser.

Neste ponto do pensamento heideggeriano, verifica-se uma transição para o que é ca racterizado como "o segundo Heidegger", que abandona a ontologia fundamental e suspende o Dasein para se concentrar na investigação da essência da poesia, na busca pela sua origem. Ta mbém, é o momento em que o filósofo incorpora o acontecimento
15. NUNES. Heidegger e a poesia, p.

16. NUNES. Heidegger e a poesia, p. 110.
EM TESE

v. 23

N. 3

SET.-DEZ. 2017

MIRANDA; PIRES. A poesia no pensamento de Heidegger e Zumthor

ค. $190-208$ 
17. CASANOVA. Compreender Heidegger, p. 241.

18. NUNES. Heidegger e a poesia, p.

19. Cf. LACOUE-LABARTHE. Poetry as experience, p. 25. histórico como fator relevante para a determinação da facticidade do homem. Deste modo, a poesia se comunica conosco diante da tensão de um momento histórico, na medida em que o poeta e nós mesmos somos seres fáticos, situados em um contexto, frutos da mencionad tensão. ${ }^{17}$ Enfim, esta rápida explanação acerca da filosofia de Heidegger foi feita para enfatizar seu caráter essencial. Conforme aponta Benedito Nunes, "jogo inocente com as palavras, o exercício da poesia é a mais perigosa das ocupações, porque, mexendo com a linguagem, mexe com a abertura e seu velamento, com a verdade e não verdade." 18

Complementarmente a este ponto de vista, Philippe Lacoue-Labarthe (1989), um filósofo francês de influência marcadamente heideggeriana, explicita essa mesma característica da poesia ao considerar que, nela, a linguagem está sempre traçando o seu próprio caminho, como um processo, de forma que expressa ou tenta expressar o brotar dela mesma em suas próprias possibilidades latentes, em seu enigma - o qual pode ser entendido como um mistério referente à constituição errante do Ser. Nessa compreensão, a poesia é tão somente o desejo de falar, pois diante da vasta a mplitude das significações, recai em uma experiência da ausência de significado, de um nada pleno porque a mplo de possibilidades. ${ }^{19}$

\section{PAUL ZUMTHOR}

Historiador e crítico literário, Paul Zumthor desenvolveu um trabalho que inicialmente se deu na área da filologia, dado seu interesse em adentrar os estudos da comunicação e linguagem poéticas concernentes à Idade Média. Como resultado, voltou-se com atenção crescente à poesia medieval, descobrindo em suas práticas orais a potencialidade em sua forma de suscitar processos diferenciados de percepção e interação.

Enquanto medievalista, Zumthor destaca-se por apresentar uma perspectiva diferenciada acerca do seu objeto, revela ndo o universo que investigava com a complexidade de quem está ciente dos desafios epistemológicos de reconstituição de um passado que está além das nossas possibilidades de experiência - ao que se refere como algo irrecuperável. ${ }^{20} \mathrm{Na}$ recusa de abordagens historicistas ou cientificistas rígidas, já com cerca de vinte e cinco a nos de carreira acadêmica, afastou-se gradativamente da filologia, da semiótica e do estruturalismo para se aproximar de um modo de análise abrangente, que incluía etnografia e fenomenologia, que compreendia o sujeito pesquisador enquanto detentor de um corpo fático, situado no mundo e determinado por questões como corporeidade, gosto e prazer.

Motivado por estes fatores, em 1980, publica Falando de Idade Média, um trabalho revisionista de métodos, que manifesta suas inquietações intelectuais, sobretudo, no que
20. ZUMTHOR. Falando de ldade Média, p. 118
EM TESE v. 23

N. 3 
21. ZUMTHOR. Falando de Idade Média, p. 28-35.

22. ZUMTHOR. Falando de ldade Média, p. 19-20.

23. ZUMTHOR. Falando de Idade Média, p. 82. tange às técnicas positivistas de produção e interpretação do conhecimento - rejeição esta que marca seu pensamento em favor de uma visão teórica que não considere os pesquisadores como "sujeitos do conhecimento", mas sim como corpos com historicidade própria. Explorando este campo de discussões, o autor sugere que a produção de conhecimento seja tomada como algo contextualizado e temporal, dado o ponto de vista inerente ao pesquisador que encontra-se arraigado na sua obra ${ }^{21}$. Por isso, os estudos do passado encontram-se entranhados pelo presente. É como se o saber fosse, em certa dimensão, uma ficção, uma vez que é uma narrativa repleta de camadas de sentido, escrita por um pesquisador que está no mundo, munido de vivências, afetos e desejos próprios. ${ }^{22}$ Assim, o saber não mais se constituiria como coisa unívoca, universal, possuidora de uma verdade absoluta e atemporal, produzido por um sujeito genérico e despersonalizado. "A filosofia construiu seu tempo: resta m os mitos que dizemos para nós, resta nossa lassidão das racionalidades falsamente tranquilizadoras, nossa necessidade do imaginário mais do que do inteligível." ${ }^{3}$

O reconhecimento da natureza provisória e circunstancial da elaboração de um saber é um ponto elementar na obra de Zumthor. Entre a fixidez do positivismo e a volubilidade de algo particular e imaginário, o a utor vê um terreno profícuo para o estabelecimento de um modo de análise, o qual deve aceitar o saber como situado em seu próprio contexto de feitura e, ainda, polissêmico, na medida em que à historicidade do autor soma-se a de quem lê - igualmente implicado no mundo. Além disso, Zumthor é reiterante no que tange à valorização do volume, do comprometimento e do engajamento do corpo na percepção de um texto. Isto dá ao conhecimento um cará ter plural, segmentado e ta mbém movente, pois se revela construído por diversos agentes, em vez de uma suposta racionalidade unívoca, imparcial e abstrata. Somam-se às lentes do pesquisador, as de quem o precedeu estudando o tema e de quem irá ler sua pesquisa. ${ }^{24}$ Neste meio, o sentido é percebido como originário de uma relação - de corporeidade e materialidades - entre um texto e um pesquisador. Ele propõe, então, que os enunciados seja $m$ abertos (mas não caóticos), e por fim, intenciona abraçar a incerteza gerada por esta dinâmica como um lugar de fala, ou melhor, um "não-lugar". ${ }^{25}$

Minha 'verdade' me implica tanto quanto meu objeto - sem, por sua vez, e em nenhum momento, nos confundir, porque ela é apenas um lugar de transição: de mim para um outro, que o meu discurso torna verossímil, mesmo quando ausente; que ele coloca em mim e em você a quem estou falando, mesmo que permaneça definitivamente desvanecido. ${ }^{26}$
24. ZUMTHOR. Falando de ldade Média, p. 28.

25. Cf. MIRANDA. A temporalidade provisória do estético como performance, p. 5531-5536.

26. ZUMTHOR. Falando de Idade Média, p. 33-4. 
27. ZUMTHOR. Falando de ldade Média, p. 63.
Dissertando sobre as contaminação da técnica sobre a linguagem das pesquisas da poesia e da literatura, Zumthor chega a apontar criticamente para o que ele chama como uma "fé inabalável na transparência da linguagem", um desejo das teorias literárias e teorias culturais das décadas de 1960 e 1970 de fazer coincidir "de modo unívoco, um significante a um significado - de tal sorte que tudo no mundo fosse legível e apropriável". ${ }^{27}$ É nesse lugar, contra esse estado de coisas, que sua pesquisa sobre a poesia oral, performance e movência advogava em favor de uma compreensão mais atenta ao particular, ao prazer, à corporeidade, à contingência de uma percepção condicionada ao aqui agora de sua configuração.

A leitura se situa tanto naquilo que foi o horizonte de espera dos Outros, jamais apagados, e no meu próprio; na escritura se pronuncia, num extremo dessa cadeia, um discurso do qual ignoro a intencionalidade e cujas determinações só posso reter parcialmente; no outro extremo, o meu, carregado de tudo o que sou, de acordo com a linguagem que me deram. Escritura/leitura, leitura/escritura, jogo de espelhos que capta o reflexo de valores mortos sob o estanho de valores vividos, speculum in aenigmate... Em verdade, as linhas que traço, ao fim das contas, não se reduzem a sua função intencional de glosa; elas constituem o lugar de troca entre dois campos de força, o do texto lido e a do meu texto leitor que, por sua vez, será lido. Eu ligo um discurso novo, ainda em processo, carregado de implicações, que apenas conheço, a um discurso suspenso sobre o seu irremediável inacabamento. ${ }^{28}$

Este panorama argumentativo construído por Zumthor, alocado em domínios hermenêuticos, relaciona-se diretamente com as percepções suscitadas nele pelo seu objeto de estudo: a poesia, o gesto e a voz enquanto práticas na Idade Média. Destaca-se, portanto, que o autor construiu sua visão contra a predominância de um tratamento anacrônico do período, que fazia com que o medievo, em muitas pesquisas, parecesse achatado e simplificado em sua verdadeira complexidade e riqueza. Uma forma de a nacronismos, por exemplo, é tratar como "literatura medieval" fenômenos que precediam à existência do livro e da letra impressa como suporte da poesia. Pode-se citar ainda o fato de que entende-se por Idade Média um período compreendido por cerca de dez séculos. Logo, indaga-se: como pode-se pretender determinar esse grande espaço de tempo como um objeto homogêneo? Por esta razão, é importante para Zumthor que seja enfatizado o quanto cada pesquisador constrói uma imagem do passado, dando ao passado um sentido próprio e fazendo dele um objeto plural, o qual, por sua vez, gerará um conhecimento que será lido de diferentes maneiras.
28. ZUMTHOR. Falando de ldade Média, p. 114. 
29. FERREIRA. Profissão medievalista, p. 196.

30. ZUMTHOR. Introdução à poesia oral, p. 166.
No que diz respeito aos aspectos da análise agregados pela poesia e pela voz, há a influência do seu estudo acerca da performance realizada pelos trovadores medievos O reconhecimento da referida provisoriedade do saber reside em uma característica que Zumthor pôde perceber por meio da tradição dos recitantes de apresentarem-se oralmente: nela, a mensagem é transmitida em um instante determinado e irreprodutível, em que a significação vêm à tona e se dissipa, ou mesmo se transmuta diante do ouvinte. Isto quer dizer que o instante em que se dá a comunicação oral preserva uma emergência de sentido indissociável do aqui e agora em que se realiza e é percebida, indissociável da dinâmica incontrolável e irreprodutível de copresenças no momento da transmissão e recepção a poesia vocal. A cada nova emissão, há uma nova forma de percepção, surgindo assim uma nova forma poética. Deste modo, a poesia vem como potencializador dessa dinâmica, como forma que não guarda em si sentidos estáveis e unívocos, mas sim a experiência da amplitude de significações, pela especificidade com que emprega a linguagem. Ademais, a projeção da voz sempre implica a mobilização do nosso corpo, ou seja, de uma presentificação psicofisiológica individual que, ao mesmo tempo, é social, ${ }^{29}$ pois como descreve o a utor, "é pelo corpo que somos tempo e lugar" ${ }^{30}$

A emanação vocal da poesia aparece, enfim, enquanto estrutura que explicita a presença de nossas historicidades na produção de sentido e de conhecimento. Partindo da a nálise do seu objeto de estudo, Zumthor faz com que suas considerações tomem proporções epistemológicas, contra uma prática teórica positivista que julgava ultrapassada. Para ele, o conhecimento deve ser entendido em suas nuances, além dos extremos entre verdadeiro ou falso - o verdadeiro se ancora no instante da percepção poética (esteja a informação partindo de qualquer suporte). A construção de sentido deve, então, ser compreendida em uma dinâmica intrincada, composta pelo corpo físico e social de seus diversos agentes, a fim de se compreender sua provisoriedade e riqueza.

Todo texto poético é, nesse sentido, performativo, na medida em que aí ouvimos, e não de maneira metafórica, aquilo que ele nos diz. Percebemos a materialidade, o peso das palavras, sua estrutura acústica e as reações que elas provocam em nossos centros nervosos. Essa percepção, ela está lá. Não se acrescenta, ela está. É a partir daí, graças a ela que, esclarecido ou instilado por qualquer reflexo semântico do texto, aproprio-me dele, interpretando-o, ao meu modo; é a partir dele que, este texto, eu o reconstruo, como o meu lugar de um dia. E se nenhuma percepção me impele, se não se forma em mim o desejo dessa (re)construção, é porque o texto não é poético; há um obstáculo que impede o contato das presenças. ${ }^{31}$
31. ZUMTHOR. Performance, recepção, leitura, p. 54.
EM TESE
BELO HORIZONTE
v. 23
N. 3
SET.-DEZ. 2017
MIRANDA; PIRES. A poesia no pensamento de Heidegger e Zumthor
P. 190-208 
32. Cf. GUMBRECHT. O corpo versus a imprensa, p. 67-96; GUMBRECHT. O autor como mascara, p. 97-108.

\subsection{EXPERIÊNCIA MODERNA EM OPOSIÇÃO À} PERFORMANCE

A partir do que foi apresentado, vemos que o pensamento de Zumthor opõe-se a certo ideal de produção do conhecimento. Tomado como fonte de uma universalidade supostamente indiscutível, o saber configurado nos moldes do positivismo intenciona a fixidez e coerência plena, almeja a atemporalidade e imparcialidade e coloca-se como uma produção de informações esterilizada da influência particular, individual ou fática. Para o autor, seria interessante se a produção do saber pudesse incluir uma faceta de imaginação e de prazer.

A emergência do livro como suporte do conhecimento e sua proliferação nos séculos iniciais da Época Moderna influem na emergência de um desejo por estabilização de sentido e de uma crença num saber despersonalizado, abstrato e atemporal - como demonstram alguns trabalhos de Hans Ulrich Gumbrecht sobre o assunto. ${ }^{32}$ A começar pelo texto escrito, pode-se dizer que a materialidade da palavra impressa no papel não se refere à mera forma de registro, mas traz consigo uma estabilização de sentido e univocidade de intenção. Retirado da dinâmica das circunstâncias moventes da comunicação vocal, o livro traz em si uma temporalidade específica, abstrata, em que a recepção do sentido do texto é distinta e distanciada do momento de elaboração e transmissão, do conta to de presenças num espaço e tempo coetâ neos ao emissor/repentista e ao receptor/ouvinte. Assim, inscrito no suporte do papel e distante da presença do autor, o sentido do texto é estabilizado, o a utor busca construir uma narrativa mais coesa e procura nos elementos pré-textuais evidenciar a intenção que perpassa toda a obra. Apartado da dinâmica dos corpos em comunicação poética oral, o que está vertido em um livro estaria pronto para ser interpretado e recebido como intencionado pelo autor. Viria daí a crença, ainda presente, de que no ato de leitura, o leitor perfaz a intenção do a utor para reconstruir o sentido do texto. Surge com o livro, fenômeno do início da modernidade - e que a caracteriza a crença de que o sentido da obra deve remeter ao sentido pretendido pelo autor. $\mathrm{O}$ sentido imanente à obra poderia assim ser acessado por aquele que a lê, como se fosse algo pronto à espera de ser fruído passivamente. Com isso, a leitura da palavra e do texto impressos torna-se uma prática de recapitulação, que nos distancia de uma participação real na produção do sentido.

No que tange à modernidade, é notório o surgimento da compreensão cartesiana que nos torna mentes pensantes sem um corpo: existimos porque pensamos, e não porque sentimos. Isto é muito significativo no estabelecimento da ideia de que o sentido advém de uma racionalidade augusta, sem corpo, que duvida do corpo, mas não do próprio duvidar, que, por sua vez, instaura a seguridade do pensar. Esta 
ausência de implicação do corpo na percepção faz parte da problematização que Zumthor coloca em torno da estrutura sujeito-objeto positivista. Em oposição a este cenário, a voz e a poesia trazem para a discussão a concepção de performance como momento em que o sentido e a percepção estão em causa coetaneamente. Este é um conceito-chave para Zumthor, que reflete a possibilidade de interação e imbricação entre corpo e obra, prazer e sentido.

Frente às tradições modernas, o autor busca a reinserção do corpo na experiência e percepção poéticas enquanto performance. Esta nada mais é do que um momento privilegiado da transmissão e da percepção que revela a forma do poético - estrutura perceptiva realizada que se dá em copresenças. Por exemplo, ao ouvir o recitar de um poema vocal, eu me presentifico com o meu corpo naquele momento, na criação de sentido daquilo que ouço, vejo e sinto, ao mesmo tempo em que o recitante também o faz e, juntos, performamos aquele instante perceptivo como forma poética. Aí habita a potencialidade virtual de uma experiência artística que se concretiza na minha percepção estética. Vale notar que a performance destaca o caráter de acontecimento da forma: como algo que emerge no instante mesmo de copresenças e coeta neidade entre produção, transmissão e percepção - para, como é o caso do acontecimento do desvela mento do Ser, desaparecer (ou ocultar-se) logo em seguida.
A performatividade em Zumthor não é exclusiva das práticas orais e poéticas. Ela também está contida na leitura de um livro ou em quaisquer outras a tividades artísticas, porém, varia nos graus de intensidade da produção de sentido por meio do sensível e do prazer poético. No caso do livro, a performance estaria em seu grau baixo, dada sua condição de fixidez e falta de interação corporal, que faz com que tenda ao fechamento e a uma intensidade menor de implicação do corpo na produção de sentido. Todavia, em obras em que o instante ou acaso são fatores determinantes, tal como é o caso de happenings ou performances de arte contemporânea, ou mesmo na performance da poesia oral, a performance alcança seu grau de intensidade máximo.

\subsection{POESIA COMO SABER DINÂMICO E MOVENTE}

Inserido nesta perspectiva de relativização da oposição entre corpo e sujeito cognoscente moderno, Zumthor trabalha a noção de movência. Este conceito, particularmente importante para a articulação de seu pensamento, é destacado em oposição à produção de conhecimento nos moldes do texto escrito.

Segundo visto, se o registro do saber sobre o papel pressupõe a fixação de um sentido único a ser acessado, gerando uma interpretação universal, suposta mente estável e recapitulável em sua integridade, a poesia e a oralidade, por sua vez, revelam uma dinâmica diferenciada no 
33. ZUMTHOR. Falando de Idade Média, p. 80. discurso, caracterizada pela abertura e pelo movimento das diferentes formas de acesso a significações plurais. Logo, entende-se que durante a percepção poética, o sentido se move diante da maleabilidade de sua construção protagonizada por diversos agentes e fatores. "Qualquer que seja com efeito, a força de uma tradição discursiva/poética, a despeito do que essa tradição tem de autodeterminado, não se poderia negar que mutações se produzem aí, de um jeito ou de outro, sob o impacto de fatores extratextuais."

Portanto, na poesia, bem como na oralidade, essa dinâmica se evidencia e se fortalece, dadas as peculiaridades de sua linguagem, que mantém as significações abertas à performatividade, e de seu modo de transmissão, que privilegia a particularidade do que ocorre no instante da percepção. A movência questiona os limites da interpretação fazendo coro à tendência contemporânea de maleabilizar construções de sentido. Todavia, isso de forma alguma implica dizer que o texto passa a ser visto como algo completamente à parte do que se põe para nós. Qualquer texto contém em si a indicação dos seus caminhos interpretativos, os quais podemos percorrer livremente em sua multiplicidade, dentro de uma dinâmica que transita pelos elementos trazidos pela obra, mas que não deve fugir deles. Em outras palavras, a obra mesma nos fornece uma matriz, e a movência não ultrapassa os limites e as regras provenientes de nossas disciplinas intelectuais. ${ }^{34}$ Por meio destas, somos levados a nos ater ao objeto apresentado e ao contexto de significações que nos circunda, o qual contém múltiplas possibilidades, dada as condições particulares de cada (re)construção de sentido. Neste espaço, o sentido se move, se mostra a cada nova percepção em outra face, mas não se perde de sua origem como virtualidade.

Estas distinções essenciais entre poesia e texto, fala e escrita, são facilmente reconhecidas no contexto do trabalho de Zumthor quando o autor confronta o seu objeto de estudo com seu método de análise. $\mathrm{Na}$ intenção de tratar o discurso poético, cujo processo de significação é lacunar e dinâmico, Zumthor se viu preso a uma exigência de linearidade e meta de sentido do texto escrito. Em virtude disto ele dá voz ao desejo de um anti-esquematismo, desejo que, na verdade, é a tentativa de realizar um sistema poético, aberto à construção de sentido. Zumthor, assim, intencionou deixar de lado a primazia da interpretação universalista em favor de um "gaio saber" e de uma "imaginação crítica" ${ }^{35}$ - um conhecimento a ser constituído de prazer, em que o discurso poético toma lugar.

Se fosse necessário categorizar uma tal prática, eu diria que nós pendemos desde então para o lado da poesia. No sentido forte e trans-histórico da palavra: relativo, não às figuras
34. ZUMTHOR. Falando de ldade Média, p. 81.

35. Cf. ZUMTHOR. Performance, recepção, leitura, p. 91-109.

EM TESE

BELO HORIZONTE

v. 23

N. 3

SET.-DEZ. 2017

MIRANDA; PIRES. A poesia no pensamento de Heidegger e Zumthor

P. $190-208$ 
36. ZUMTHOR. Performance, recepção, leitura, p. 105. da linguagem como tais, mas a uma maneira de conhecer o mundo, uma modalidade eminente do saber. Informação, coleta dos fatos, descrição de processos externos, contribuições de disciplinas a nexas ou vizinhas (linguística ou antropologia): tudo isto, mantido de pleno direito (e, se possível aprofundado), a "poesia" domina, controla, faz disso sua matéria. Mas ela recusa lhe emprestar sua forma: ela não pode. Sua forma é imagem: fruto de uma operação pessoal, cujas regras heurísticas se fundamentam num sedimento de experiências mal comunicáveis como tal, inexplicitáveis, injustificáveis, aprisionadas nos limites (largos ou estreitos, outra questão) de um indivíduo vivo. Falemos a esse propósito de “imaginação", sem acossar mais a palavra. ${ }^{36}$

\section{A POESIA EM HEIDEGGER E ZUMTHOR}

Até aqui, verificou-se que a poesia pode ser uma manifestação diferenciada das demais formas de comunicação protagonizadas pelo ser humano. Cientes do lugar que essa linguagem ocupa no trabalho de Heidegger e Zumthor, retoma-se a proposta geral do artigo para analisar os possíveis paralelos entre os referidos a utores no que diz respeito à temática enfocada.

Primeiramente, é notório que, tanto em Heidegger como em Zumthor, a poesia seja concebida como um elemento que exponha o indivíduo dentro de sua historicidade.
Conforme o pensamento de Heidegger, vê-se que "todas as épocas são marcadas por uma verdade específica, porque todas elas dão voz a um campo de desvelamento e a um âmbito de retração [do Ser]." ${ }^{37}$ Nesta perspectiva, existe um contexto histórico que permite que o Ser seja revelado em certos aspectos e, concomitantemente, velado em outros, pois cada período da história tem uma forma de utilização da linguagem instaurada, que se modifica conforme os acontecimentos. Neste quadro, a obra de arte emerge como um campo de tensão, porque, enquanto fruto de sua própria época, abriga e traz à tona as contradições latentes de sua origem. Consequentemente, o poeta torna-se voz do seu tempo, ao abrir espaço para que tais tensões, de velamento e desvelamento, se manifestem em sua poesia, fazendo dela a linguagem do Ser. ${ }^{38}$

De modo similar, Zumthor afirma o poder da poesia de revelar os comportamentos de uma época, alinhado ao aludido enfoque das historicidades e especificidades que permeiam cada um de nós como produtores de saberes, pesquisadores e também participantes do acontecimento vocal. Assim como a produção de conhecimento carrega consigo parte do sujeito que lhe dá origem, sua temporalidade e provisoriedade intrínsecas, a poesia também o faz. Antes da avaliação acerca do discurso poético, é possível identificar que a rejeição de um racionalismo técnico, que permeia não apenas o âmbito da produção de conhecimento
37. CASANOVA. Compreender Heidegger, p. 238.
38. Cf. CASANOVA. Compreender Heidegger, p. 238. 
como ta mbém nosso cotidiano, habita o pano de fundo da teoria de ambos pensadores. Para Heidegger, "a cegueira cresce a ponto de já não se poder ver como a europeização do homem e da terra faz secar a própria fonte do que é essencial. ${ }^{39}$ Nesta linha, os dois estudiosos criticam, então, o legado de um pensamento moderno que contamina o contemporâneo, que almeja tecnicizar e restringir nossa experiência, como se tudo se tratasse de um objeto de estudo objetiva mente apreensível, em vez de se voltar para a riqueza de sua multiplicidade. Aliado a isto, há a concepção cartesiana de que somos acima de tudo mentes incorpóreas, ou mesmo "sujeitos transcendentais" e, somente de modo secundário, corpos providos da capacidade de experimentar o mundo em sua facticidade, em seus processos de singularização.

Em vista desta problemática, Heidegger compreende, em seu tempo, a especificidade da forma com a qual os modos de acesso ao mundo precisam ser tratados, a partir da questão da referencialidade dos objetos apreendidos por nossa mente e corpo, situados no mundo e percebidos por um ser-no-mundo. Assim, ele marca sua presença nas futura gerações de pesquisadores. Zumthor, no que lhe concerne, além de leitor de Heidegger, se vale da fenomenologia de Maurice Merleau-Ponty, que, direta mente influenciado por Heidegger, argumenta acerca da interdependência entre corpo e mente, ressaltando então a importância de nossas experiências empíricas contextualizadas. Em outros termos, como descreveria o próprio Zumthor em uma apreensão fenomenológica, deve-se considerar a percepção fundada em um ser com "uma estatura, um peso, uma constelação original de traços físicos e psíquicos".$^{40}$ E completa:

Meu corpo é uma materialização daquilo que me é próprio, realidade vivida que determina minha relação com o mundo. Dotado de uma significação incomparável, ele existe à imagem de meu ser: é ele que eu vivo, possuo e sou, para o melhor e para o pior. Conjunto de tecidos e de órgãos, suporte da vida psíquica, sofrendo ta mbém de pressões do social, do institucional, do jurídico, os quais, sem dúvida, pervertem nele seu impulso primeiro. ${ }^{41}$

Neste sentido, contra estruturas racionalistas, Heidegger e Zumthor criticam o que se entende como um pensamento enfatica mente voltado ao técnico, a feito às práticas científicas fundadas no positivismo. Na perspectiva heideggeriana, a ciência restringe-se aos entes, que são tomados como coisas dadas de modo simples a partir de sua funcionalidade - o que finda por deixar de lado a ampla significação de que podem ser detentores. $\mathrm{Na}$ mesma linha de raciocínio, Zumthor reafirma que a pretensão de universalidade positivista não comporta a amplitude dos
39. HEIDEGGER. A caminho da linguagem, p. 84.

40. ZUMTHOR. Performance, recepção, leitura, p. 23.
41. ZUMTHOR. Performance, recepção, leitura, p. 23-24. 
sentidos em sua complexidade e riqueza, e que, quando sim, produz significações estanques e generalizadas, subtraídas das manifestações do particular.

Como consequência deste quadro instaurado, não raro a linguagem adquire uma função meramente representacional. A palavra obtém o sta tus de signo, vivendo uma espécie de degradação mediante suas possibilidades: recai no esquecimento do Ser. Em uma cisão com o que Heidegger e Zumthor assumem como utilização precária da linguagem, como apontado aqui em suas respectivas argumentações, a poesia emerge como lugar privilegiado de manifestação da linguagem. Com base no que propõem os autores, a poesia se enraíza em um modo diferenciado de emprego da linguagem, que preserva a abertura da palavra em sua possibilidade de revelar o Ser. Deste modo, é especialmente nesse domínio que se encontram as noções de movência e velamento/desvelamento: se Zumthor defende a ideia da movência de sentido que está presente em todos os textos, mas que se potencializa ao máximo na poesia oral, Heidegger vê na poesia um espaço em que o sentido de abertura da linguagem se revela e, ao mesmo tempo, se oculta. A verdade experienciada na dinâmica de vela mento/desvelamento é considerada como movimento incapaz de dar acesso totalizante ao que está disponível no poema, à plenitude de suas significações, tal qual Zumthor vê nossa relação movente com o discurso poético - movente no sentido de reiterante, mas nunca exata mente reprodutível como sentido idêntico e permanente. Para ele, sempre há um "original irrecuperável”, e diferentes camadas de sentido que podem ser acessadas, porém nunca em sua totalidade apreensível, pois o conhecimento e o poético são de natureza provisória.

Analisando desta forma, podemos verificar que, no espaço potencial em que se encontram as possibilidades de significação, Heidegger visa o abrir-se para a multiplicidade do Ser. "A linguagem da poesia é essencialmente polissêmica e isso de um jeito muito próprio. Não conseguiremos escutar nada sobre a saga do dizer poético enquanto formos ao seu encontro guiados pela busca surda de um sentido unívoco." ${ }^{42} \mathrm{E}$ em outra passagem, completa: "Afirmar o sentido imperativo do 'que seja' como o único possível seria, no entanto, por demais violento. É possível que, na saga poética do dizer, o 'que seja' oscile entre um sentido e outro, entre o sentido do cha mado como reivindicação e o de uma articulação e sintonia com o chamado." ${ }^{\text {‘3 }}$ Ao mesmo passo, Zumthor indica-nos a prática de uma abertura para $o$ inesperado, no que diz respeito aos diferentes significados que podem ser providos:

Praticar aí uma abertura sobre o que o nosso discurso fechou por sua própria finitude; levar o produto, "finito", à
42. HEIDEGGER. A caminho da linguagem, p. 63.

43. HEIDEGGER. A caminho da linguagem, p. 129 

44. ZUMTHOR. Falando de Idade sua produção in-finita; desconstruir um objeto designado, por hipótese, como montagem. Montagem das relações que com-põem e que necessariamente ele pressupõe, mas essas relações se ligam em configurações móveis, cuja identidade não se torna apreensível, senão no nível mais geral comum. $^{44}$

Sendo assim, podemos sugerir que o anti-esquema tismo de Zumthor, que o leva a um "não lugar" hermenêutico, pode se relacionar com uma experiência relativa ao colocar-se à disposição para as possibilidades de significação, em um espaço de indeterminação que compreende a plurivocidade dos significados: um espaço em que esta ría mos sujeitos a vivenciar o desvelamento/velamento do Ser. Poderia ser descrito como a titude de assumir uma postura filosófica (uma disposição existencial, Stimmung), na qual nos colocaríamos a tentos ao chamamento, em que, conscientes da historicidade e apartados de pensamentos pré-estabelecidos, experimentaría mos o olhar as coisas dentro de suas múltiplas significações; um olhar poético.

Longe da meta de sentido cotidiana, suas argumentações alavancam discussões que enfocam a poesia como campo de possibilidades para a manifestação de múltiplas significaçoes, abarcando o conhecimento em sua complexidade. Habita em seus trabalhos uma afinidade no que diz respeito à vontade de se construir um saber através da poesia. Para Heidegger, os poetas e filósofos se destacariam da munda nidade, munidos do acesso aos meios necessários para fazerem-se atentos ao chamado do Ser, uma vez que o olhar voltado para o Ser é o que se constitui uma verdadeira fonte de saber. Em Zumthor, vê-se o entusiasmo em aderir ao discurso poético como forma de gerar conhecimento diverso, sem tendência ao universal, no qual reside uma genuína compreensão da riqueza dos objetos. Em ambos a utores, a linguagem ou pensamento técnico não são, portanto, suficientes. A poetização do saber é uma chave entre eles, cujas lacunas estão abertas para a manifestação da diversidade.

\section{REFERÊNCIAS}

CASANOVA, Marco Antônio. Compreender Heidegger. São Paulo: Editora Vozes, 2009

DANTAS, Viviane Maria. O papel da linguagem no pensamento de Heidegger. In: Revista de Ciências Humanas UNITAU, Taubaté n. 4, vol. 2, ago-dez/2011, p. 16-26.

GIACOIA, Oswaldo. Heidegger urgente. São Paulo: Três Estrelas, 2013

GUMBRECHT, Hans Ulrich. O corpo versus a imprensa: os meios de comunicação no início do período moderno. In:

Modernização dos sentidos. Tradução Lawrence Flores Pereira. São Paulo: Ed. 34, 1998, p. 67-96; 
GUMBRECHT, Hans Ulrich. O autor como mascara. Contribuição à arqueologia do imprenso. In: Modernização dos sentidos. Tradução Lawrence Flores Pereira. São Paulo: Ed. 34, 1998, p. 97-108.

\section{HEIDEGGER, Martin. Conferências e escritos filosóficos.} Tradução Ernildo Stein. São Paulo: Abril Cultural, 1973 (Os Pensadores, XLV)

HEIDEGGER, Martin. Carta sobre o Humanismo. Tradução Rubens Eduardo Frias. São Paulo: Editora Moraes، 1991.

HEIDEGGER, Martin. Sobre a essência da linguagem. Tradução Énio Paulo Gichini. São Paulo: Editora Vozes, 1999.

HEIDEGGER, Martin. Ser e tempo. Tradução Márcia Schuback. São Paulo: Editora Vozes, 2005

HEIDEGGER, Martin. A caminho da linguagem. Tradução Marco Antônio Casanova São Paulo: Editora Vozes, 2015.

LACOUE-LABARTHE, Philippe. Poetry as Experience. Tradução Roxanne Lapidus. In: Substance, Wisconsin, n. 3, vol. 18, jun/1989, p. 22-29.

MIRANDA, Mariana Lage. A temporalidade provisória do estético como performance. In: Anais eletrônicos do XV encontro ABRALIC, Rio de Janeiro: Dialogart Publicações, 2017, p. 5531. 5542

NUNES, Benedito. Heidegger e a Poesia. In: Natureza humana São Paulo, n. 1, vol. 2, jun/2000, p. 103-127.
PIRES FERREIRA, Jerusa. Profissão Medievalista. In: Signum, São Paulo, n. 1, vol. 1, nov/1999, p. 185-205.

ZUMTHOR, Paul. Performance, recepção, leitura. Tradução de Jerusa Pires Ferreira e Suely Fenerich. São Paulo: Cosac Naify, 2007

ZUMTHOR, Paul. Falando de Idade Média. Tradução de Jerusa Pires Ferreira. São Paulo: Editora Perspectiva, 2009.

ZUMTHOR, Paul. Introdução à poesia oral. Tradução de Jerusa Ferreira, Maria Lúcia Diniz Pochat, Maria Inêz de Almeida. Belo Horizonte: Editora UFMG, 2010

Enviado em 18-07-2017 Aceito em 15-02-2018. 